\title{
Haptic and kinesthetic estimates of length
}

GORDON STANLEY 1

INDIANA UNIVERSITY

Twenty-two students made magnitude estimates of the lengths of rods held between their index fingers (haptic condition) and also estimates of the separation of their index fingers without the rods present (kinesthetic condition). The rods ranged in length from 0.70 to $33 \mathrm{in.}$ increasing in length by approximately equal logarithmic steps. The exponents of the power functions for magnitude estimates of length under haptic and kinesthetic conditions were 1.05 and 0.94 respectively.

Over the last decade there has been considerable interest in investigating the relationship between sensory and stimulus magnitudes by the direct method of magnitude estimation (e.g., Stevens \& Galanter, 1957). Several reports indicate that visual estimates of length obtained by the method of magnitude estimation are linearly related to physical length (Ekman \& Junge, 1961; Stevens \& Galanter, 1957; Teghtsoonian, 1965). These studies have reported exponents of the power function ranging from 0.95 to 1.11 .

The relationship between haptics (active touch) and vision has received extensive theoretical treatment by Gibson (1962), who has drawn attention to similarities between the two systems. Rudel \& Teuber (1963) found that the initial size of the Mueller-Lyer illusion was essentially identical for visual and haptic groups. Recently Teghtsoonian \& Teghtsoonian (1965) obtained magnitude estimates of lengths of rod under two conditions. In one condition Ss were blind-folded and felt the lengths of the rods using their index fingers, and in the other condition they were able to see, but not touch, the rods. The exponent of the power function for touch was 0.983 and that for vision was 1.007 .

In the touch condition of the Teghtsoonian \& Teghtsoonian (1965) experiment, Ss had at least two conceptually distinguishable information inputs: information from the touch receptors and also from the kinesthetic (muscle-position) sense. The present experiment was designed to compare Ss performance in estimating lengths under a similar touch (haptic) condition with their performance when estimates of length were obtained by judging the separation of the two index fingers without touch stimulation (kinesthetic). Subjects

Ss were 18 females and four males from an introductory psychology class at Indiana University。

\section{Apparatus}

Ss placed their hands under an $8 \mathrm{in.} \mathrm{high} \mathrm{wooden}$ bridge which covered the top of a table $40 \mathrm{in}$. by $20 \mathrm{in}$. A cloth screen was hung on Ss side of the bridge covering his arms when they were placed over the table. Es side of the bridge was open so $E$ could hand rods to $S$ and separate Ss figures. There were eight rods made from $3 / 8 \mathrm{in}$. wood dowelling, their respective lengths being $0.70,1.25,2.20,4.00,7.10,13.00,23.00$ and $33.00 \mathrm{in}$. These lengths were also marked on the table-top for use in the kinesthetic condition.

\section{Procedure}

All Ss made estimates under both haptic and kinesthetic conditions. Ss were assigned at random to two groups, one group being presented first with haptic and the other first with kinesthetic stimulation. Ss were tested individually and were seated in front of the stimulus box. E read the following instructions: "In this experiment we are concerned with judgments of length by feeling. Will you place this blind-fold over your eyes. I want you to close your hands and extend your index fingers ( $E$ assists). Now place your hands under this box (E guides). I will place your index fingers at the ends of lengths of rod and you will be required to estimate the length of the rod in inches or fractions of an inch. (I will move your hands apart and you will be required to estimate the distance between your two index fingers.)"

For the kinesthetic condition $\mathrm{E}$ separated Ss hands so that the distance between the insides of the index fingers corresponded to marked lengths (seen only by $E$ ) on the table-top. In each condition $E$ presented the stimuli so that the distances were always symmetrical with respect to the center of S's body.

\section{Results and Discussion}

The judgments were pooled over Ss and geometric means were calculated for each stimulus length. Using the method of averages (Lewis, 1960, p. 13) linear functions were obtained for log geometric mean estimate $(\mathrm{Y})$ against log physical length (X). The respective

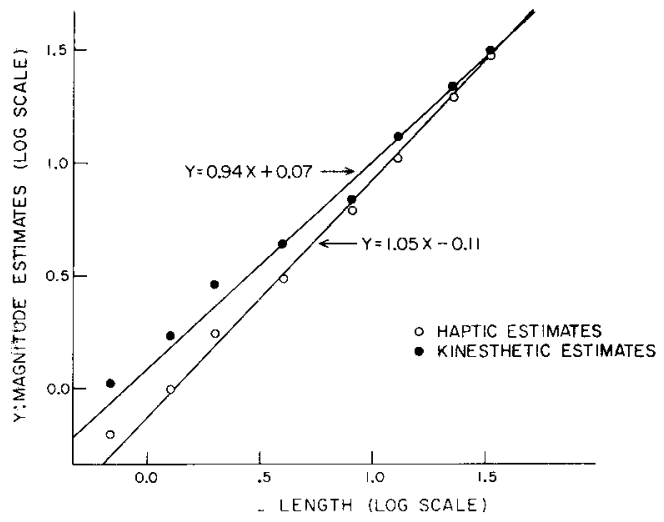

Fig. 1. Log geometric mean haptic and kinesthetic estimates plotted against log physical length. 
functions for haptic and kinesthetic estimates were $\mathrm{Y}=$ $1.05 X-0.11$ and $Y=0.94 X+0.07$. The variances of the residuals were 0.0008 and 0.0033 respectively. Figure 1 shows log geometric means plotted against log physical length and indicates the slope of the derived functions. Similar fits were obtained for individual Ss and treating the exponents of $\mathrm{X}$ as scores no differences between means were found due to order of presentation of conditions. It was noticed that the exponents for the kinesthetic condition were consistently smaller than for the haptic condition. A t-test for related samples indicated that this difference was significant $(t=5.3, p>.01)$.

In both haptic and kinesthetic conditions of stimulation estimates are close to veridical values and the exponents of the power functions (1.05 and 0.94 , respectively) fall within the previously reported ranges for visual estimation of length (e.g., Stevens \& Galanter, 1957) and touch (Teghtsoonian \& Teghtsoonian, 1965). From Fig. 1 it can be seen that for smaller distances touch enables a more accurate estimate than kinesthesis. As distance increases, it appears that touch information tends to become redundant for accurate estimation of length.

\section{References}

Ekman, G., \& Junge, K. Psychophysical relations in visual perception of length, area, and volume. Scand. J. Psychol., 1961, 2, $1-10$.

Gibson, J. J. Observations on active touch. Psychol. Rev., 1962, 69, 477-491.

Lewis, 0. Quantitative methods in psychology. New York: McGrawHill, 1960 .

Rudel, R. G., \& Teuber, H. L. Decrement of visual and haptic Mueller-Lyer illusion on repeated trials: a study of cross-modal transfer. Quart. J. exp. Psychol., 1963, 15, 125-131.

Stevens, S. S., \& Galanter, E. H. Ratio scales and category scales for a dozen perceptual continua. J. exp. Psychol., 1957, 54, $377-411$.

Teghtsoonian, M. The judgment of size. Amer. J. Psychol., 1965, $78,392-402$.

Teghtsoonian, M., \& Teghtsoonian, R. Seen and felt length. Psychon. Sci., 1965, 3, 465-466.

\section{Note}

1. The author is grateful to Lee Price for assistance in collecting these data. 